\title{
The factor structure of the Center for Epidemiological Study - \\ Depression Scale in people with multiple sclerosis [version 1;
}

\section{peer review: 2 approved]}

\author{
Ian I. Kneebone (id)1, Chris Fife-Schaw (D2), Lawrence T. Lam¹,3, Roshan das Nair \\ ${ }^{1}$ Discipline of Clinical Psychology, Graduate School of Health, University of Technology Sydney, Ultimo, NSW, 2007, Australia \\ ${ }^{2}$ School of Psychology, University of Surrey, Guildford, Surrey, GU2 7XH, UK \\ ${ }^{3}$ Vice President (Academic), Tung Wah College, Hong Kong, Homantin, SAR, Hong Kong \\ ${ }^{4}$ Division of Psychiatry and Applied Psychology, School of Medicine, University of Nottingham, Lenton, Nottingham, \\ Nottinghamshire, NG7 2RD, UK
}

V1 First published: 25 Aug 2020, 9:1038
https://doi.org/10.12688/f1000research.25129.1
Latest published: 25 Aug 2020, 9:1038

https://doi.org/10.12688/f1000research.25129.1

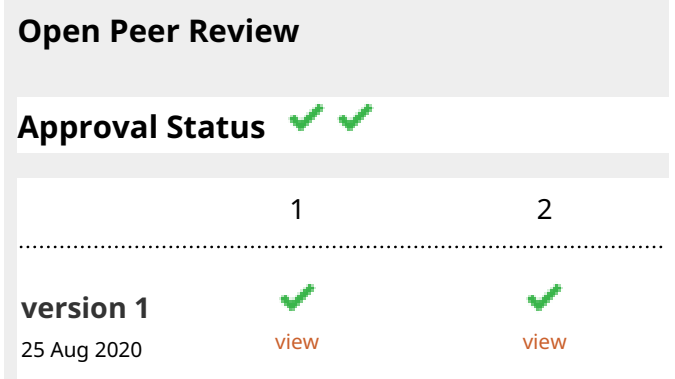

1. Daphne Kaklamanou, University of Portsmouth, Portsmouth, UK

2. Bilge Piri Cinar, Zonguldak Bülent Ecevit University, Zonguldak, Turkey

Any reports and responses or comments on the article can be found at the end of the article. 
Corresponding author: Ian I. Kneebone (ian.kneebone@uts.edu.au)

Author roles: Kneebone II: Conceptualization, Investigation, Methodology, Project Administration, Resources, Supervision, Validation, Visualization, Writing - Original Draft Preparation, Writing - Review \& Editing; Fife-Schaw C: Conceptualization, Data Curation, Formal Analysis, Methodology, Resources, Software, Validation, Visualization, Writing - Original Draft Preparation, Writing - Review \& Editing; Lam LT: Conceptualization, Formal Analysis, Methodology, Validation, Visualization, Writing - Review \& Editing; das Nair R: Conceptualization, Methodology, Validation, Visualization, Writing - Original Draft Preparation, Writing - Review \& Editing

Competing interests: No competing interests were disclosed.

Grant information: Financial support was provided through the UK National Health Service, Research and Development Fund, Budget 1.

Copyright: @ 2020 Kneebone II et al. This is an open access article distributed under the terms of the Creative Commons Attribution License, which permits unrestricted use, distribution, and reproduction in any medium, provided the original work is properly cited.

How to cite this article: Kneebone II, Fife-Schaw C, Lam LT and das Nair R. The factor structure of the Center for Epidemiological Study - Depression Scale in people with multiple sclerosis [version 1; peer review: 2 approved] F1000Research 2020, 9:1038 https://doi.org/10.12688/f1000research.25129.1

First published: 25 Aug 2020, 9:1038 https://doi.org/10.12688/f1000research.25129.1 


\section{Introduction}

Multiple sclerosis (MS), a disease of the central nervous system, involves a variety of debilitating physical, sensory, cognitive and emotional symptoms. People with MS (PwMS) are typically diagnosed aged 20-40 years and often face psychosocial consequences including disruptions to life goals, education/ employment, income, relationships, leisure activities, and daily living activities ${ }^{1}$. Indeed, MS is considered the leading cause of disability in young adults in the developed world ${ }^{2}$. Furthermore, the chronic and unpredictable course of MS and side effects of MS-related medications have profound social and psychological consequences ${ }^{3}$.

Depression is common in PwMS with a point prevalence rate of up to $40 \%$ and up to $50 \%$ experiencing it at some time post diagnosis ${ }^{4,5}$. Depression is also associated with higher suicidal ideation and attempts in pwMS ${ }^{6}$ and often disrupts relationships and reduces compliance with MS disease-modifying treatments ${ }^{7}$. The negative sequelae associated with depressive symptoms in MS also include decreased perceived cognitive function $^{8}$, increased fatigue ${ }^{9}$, and sleep difficulties ${ }^{10}$.

Depressive symptoms in MS may not only be caused by the psychosocial adjustment to the illness and its affects but in relate to biological aspects of the disease ${ }^{11}$. Organic changes, including in, neuroendocrine function, inflammatory process and brain associated brain damage likely to play a role ${ }^{12-14}$.

Depression is assessed by clinical interviews but is more often assessed (especially in research contexts) through self-report questionnaires. There is a significant overlap between the somatic symptoms common to depression and MS symptoms, principally fatigue, poor sleep and concentration. This overlap has led to concerns over the accuracy of assessment of depression in PwMS ${ }^{15}$. Furthermore, some self-report measures of depression include questions about health and work difficulties, which are also impacted by MS-related physical disability ${ }^{16}$. As such, levels of depression in MS may be over- or underestimated, particularly when using self-report measures.

Despite the Center for Epidemiological Studies - Depression Scale $(\mathrm{CES}-\mathrm{D})^{17}$ originally being developed for use with the general community ${ }^{18}$ it has become to widely used in clinical research and practice settings, including with PwMS ${ }^{19}$. The original CES-D is a 20-item self-reported scale that has been shown to measure depressive symptoms across four domains: Depressed Affect, Positive Affect, Somatic Complaints/Activity Inhibition, and Interpersonal Difficulties ${ }^{18}$. The four original latent factors have been replicated in numerous populations ${ }^{20}$. However, a number of other studies have yielded different CES-D factor structures. For instance a three-factor solution was evident in Chinese adolescents ${ }^{21}$ and as many as five factors has been found in a random sample of adults in the USA ${ }^{22}$. Some studies have also shown the presence of variation in the items comprising each factor $^{23,24}$ and the magnitude of item loadings has varied across clinical groups ${ }^{25}$. Variations such as these may affect the sensitivity and specificity of this instrument in detecting depressive symptoms in different populations and question the test's validity. With respect to PwMS, Amtmann et al. ${ }^{26}$ confirmed acceptable inter-item reliability and convergent/ discriminant validity of the CES-D in a sample of 455 patients. However, in this study, confirmatory factor analysis was only used to consider the presence of a single factor, depression, i.e., unidimensionality. One study considered the multi-dimensional factor structure of the French version of the CES-D in people with MS, confirming the initially identified four factor structure ${ }^{27}$.

Consistent with concerns that different populations can produce different factor analytic structures for measures ${ }^{28,29}$ and this pertains to validity ${ }^{30}$, the current study aimed to assess whether the four-factor model of depression is supported in PwMS in an English language version of the CES-D.

\section{Methods}

The research was approved by the University of Surrey Advisory Committee on Ethics [ACE/99/30/Psych]. Participants were those who had provided written, informed consent to take part in a large three-phase longitudinal study of depression in PwMS commencing in $1999^{31}$ Participants were required to have a diagnosis of MS and be 18 years or older. Only participants under the age of 65 years were included in the current study. Participants were a convenience sample who self-referred to the study following the publication of an article in an MS magazine available to people in the United Kingdom. Data, including the CES-D, were collected yearly by postal survey using a prepaid system, on three occasions. The CES-D data collected at phase 1 are reported here. No power analysis to determine sample size was calculated a priori.

\section{Measures}

The CES-D ${ }^{17}$ requests the self-reporting of depressive symptoms experienced over the previous week. The 20 items are rated on a ' 0 ' to ' 3 ' scale, with a higher rating indicating greater symptom frequency. Scores can range from 0 to 60 . The CES-D is considered to be relatively unaffected by somatic variables ${ }^{32}$ and has been used in studies considering depression in PwMS ${ }^{19}$.

\section{Data analysis}

Data analysis was performed using SPSS v25. The data set was split into two by a random selection process to create an exploratory model development sample and the validation sample. In the exploratory stage, a model based on Radloff's ${ }^{17}$ original specification of the CES-D was tested using confirmatory factor analysis (CFA). Model fit and the degree of specification errors were examined and modifications of the original model made as indicated and re-tested in the exploratory sample. This specification search involved examination of modification indices, identification of non-significant paths and conceptual acceptability. In the second stage, the revised model was tested in the confirmation sample to assess reproducibility. Models were estimated using maximum likelihood estimation and adequacy of fit was assessed using criteria proposed by $\mathrm{Hu}$ and Bentler $^{33}$ for CFA models. These criteria of goodness of fit are a non-normed fit index/Tucker Lewis index (NNFI/TLI) $>0.95$, comparative fit index $(\mathrm{CFI})>0.95$, root mean square error of approximation (RMSEA) $<0.06$ and standardized root mean square 
residual $(\mathrm{SRMR})<0.08$. For completeness we also report the traditional chi-square fit index and the reduced chi-squared statistics $\left(\chi^{2} / \mathrm{df}\right)$, which should ideally be less than $2^{34}$. To determine internal reliability of each factor Cronbach's alpha coefficients were calculated. Due to a typographical error in one of the items (item 10: 'I felt fearful' was printed as 'I felt tearful') in the questionnaire used ${ }^{\mathrm{a}}$, which was only observed after data collection; this item had to be removed, and the analyses are reported on the 19 items. The exploratory and confirmatory factor analyses were performed again on the full 20 items.

\section{Results}

Participants

A total of 493 participants were recruited ( $n=399$ women). The age range was 22 years to 65 years (mean, $X=45.8$ years, SD = 9.25). MS diagnoses sub-types were as follows: $45 \%$ had 'relapsing remitting type', $20 \%$ had 'secondary progressive type', $10 \%$ has 'primary progressive type', and 19\% 'did not know' their MS sub-type, with 5\% 'missing data'. Over half $(62.9 \%)$ of participants scored $>16$ on the CES-D, the cut off indicating 'significant depressive symptoms' $(\mathrm{X}=22.1, \mathrm{SD}=12.57$, Range 0-59).

\section{Data set}

Since there was only one sample for factor analyses, both exploratory and confirmatory, the original data set consisting of 493 patients was split into two using SPSS's random selection process. Only cases with complete data on all 20 CES-D items $(n=472)$ were retained and as a result, a model specification sample with 235 participants was generated and the remaining 237 were used as the validation sample.

\section{Confirmatory factor analysis in the exploration sample}

Following Radloff's ${ }^{17}$ exploratory factor analyses we assessed the fit of our data to her original model with the omission of item 10. Table 1 gives the fit indices for this initial model (Model 1). These indices suggest that the model, while not unreasonable in terms of the absolute size of the indices, is mis-specified. A specification search suggested that the two Somatic Symptoms items 'I felt everything that I did was an effort

a We used the photocopy-permitted master copy of the scale from the Measures in Health Psychology: A User's Portfolio (Johnston, Wright, \& Weinman, 1995). An erratum for this measure has now been issued.
(CESD7)' and 'I could not get going (CESD20)' shared variance not entirely captured by the Somatic Symptoms factor $(\mathrm{MI}=10.21)$ so a second model with this term added was assessed. Fit indices for this model (Model 2) are presented in Table 1. On $\mathrm{Hu}$ and Bentler's ${ }^{33}$ four criteria this model fits acceptably and the $\chi^{2} / \mathrm{df}$ criterion is also satisfactory. No further modifications were made as these either made trivial improvements in fit or did not make sense theoretically.

The re-specified model was then assessed in the confirmation sample (Model 3) and as seen in Figure 1, the fit indices suggest a satisfactory fit of this modified four-factor model. Indeed, the fit indices are slightly better in the confirmation sample than the exploratory one. The modification made in the re-specification process did not imply factorially complex items nor that the basic four-factor CES-D model was substantively incorrect, so we estimated the standard Cronbach's Alpha reliability coefficients for the implied CES-D subscales in the confirmation sample. These were 0.81 for Positive Affect, 0.87 for Depressed Affect, 0.73 for Somatic Symptoms and 0.79 for Interpersonal Problems.

For the 20-item scale, following Radloff's ${ }^{17}$ exploratory factor analyses we assessed the fit of our data to her original model. Table 2 gives the fit indices for this initial model (Model 1). These indices suggest that the model, while not unreasonable in terms of the absolute size of the indices, is mis-specified. A specification search suggested a substantial correlation between the error terms associated with the depressed affect items 'I felt tearful (CESD10)' and 'I had crying spells (CESD17)' needed to be modelled $(\mathrm{MI}=51.92)$ so a second model with this term added was assessed. This correlated error term reflects the incorrect wording of Item 10 we identified in the Johnston et al. ${ }^{35}$ version of the CES-D we used. Fit indices for this model (Model 2) are presented in Table 2. On three of $\mathrm{Hu}$ and Bentler's ${ }^{33}$ four criteria this model fits acceptable in the $\chi 2 / \mathrm{df}$ is also satisfactory. The addition of this path in the model suggests that these two items share variance $(r=0.48)$ in this PwMS sample that is not captured solely by Depressed Affect. Further inspection of model mis-fit suggested that the two Somatic Symptoms items 'I felt everything that I did was an effort (CESD7)' and 'I could not get going (CESD20)' also shared variance not entirely captured by the Somatic Symptoms factor $(\mathrm{MI}=11.08)$. Indices for this model (Model 3) are presented in Table 2 and Figure 2 and suggest a good fit against the criteria. No further modifications were made as these

Table 1. Goodness-of-fit statistics for the models tested - with item 10 removed.

\begin{tabular}{|c|c|c|c|c|c|c|c|c|}
\hline Model & Description & $\chi^{2}$ & Df & $\chi^{2} / \mathrm{df}$ & NNFI/TLI & CFI & RMSEA & SRMR \\
\hline 1 & As specified in Radloff (1977, minus Item 10) & 233.05 & 146 & 1.60 & .948 & .955 & .050 & .048 \\
\hline 2 & $\begin{array}{l}\text { Model } 1 \text { with correlated error terms for items } \\
\text { CESD7 and CESD20 }\end{array}$ & 218.60 & 145 & 1.51 & .955 & .962 & .047 & .046 \\
\hline 3 & $\begin{array}{l}\text { Model } 2 \text { tested with the confirmation sample } \\
\text { data }\end{array}$ & 213.84 & 145 & 1.48 & .959 & .965 & .045 & .046 \\
\hline
\end{tabular}




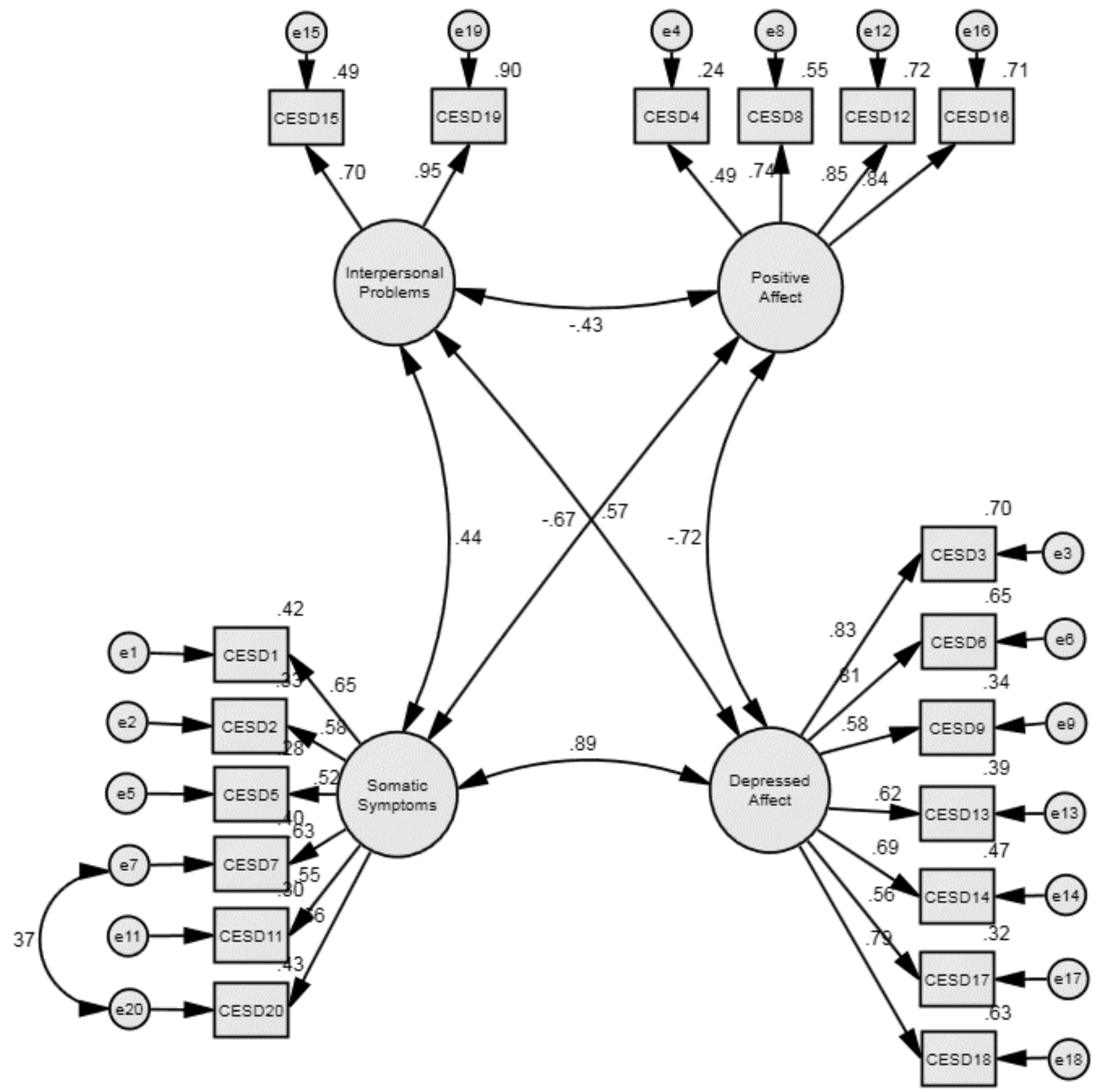

Figure 1. Revised CES-D model for People with MS - with item 10 removed. Figures are standardised maximum likelihood estimates.

Table 2. Goodness-of-fit statistics for the models tested - for the 20-item scale.

\begin{tabular}{|c|c|c|c|c|c|c|c|c|}
\hline Model & Description & $\chi^{2}$ & df & $\chi^{2} / \mathrm{df}$ & NNFI/TLI & CFI & RMSEA & SRMR \\
\hline 1 & As specified in Radloff1 & 328.04 & 164 & 2.00 & 0.912 & 0.924 & 0.065 & 0.051 \\
\hline 2 & $\begin{array}{l}\text { Model } 1 \text { with correlated error terms for } \\
\text { items CESD10 and CESD17 }\end{array}$ & 271.26 & 163 & 1.66 & 0.942 & 0.950 & 0.053 & 0.049 \\
\hline 3 & $\begin{array}{l}\text { Model } 2 \text { with correlated error terms for } \\
\text { items CESD7 and CESD20 }\end{array}$ & 255.83 & 162 & 1.58 & 0.949 & 0.957 & 0.050 & 0.046 \\
\hline 4 & $\begin{array}{l}\text { Model } 3 \text { tested with the confirmation sample } \\
\text { data }\end{array}$ & 240.93 & 162 & 1.49 & 0.957 & 0.963 & 0.045 & 0.047 \\
\hline
\end{tabular}




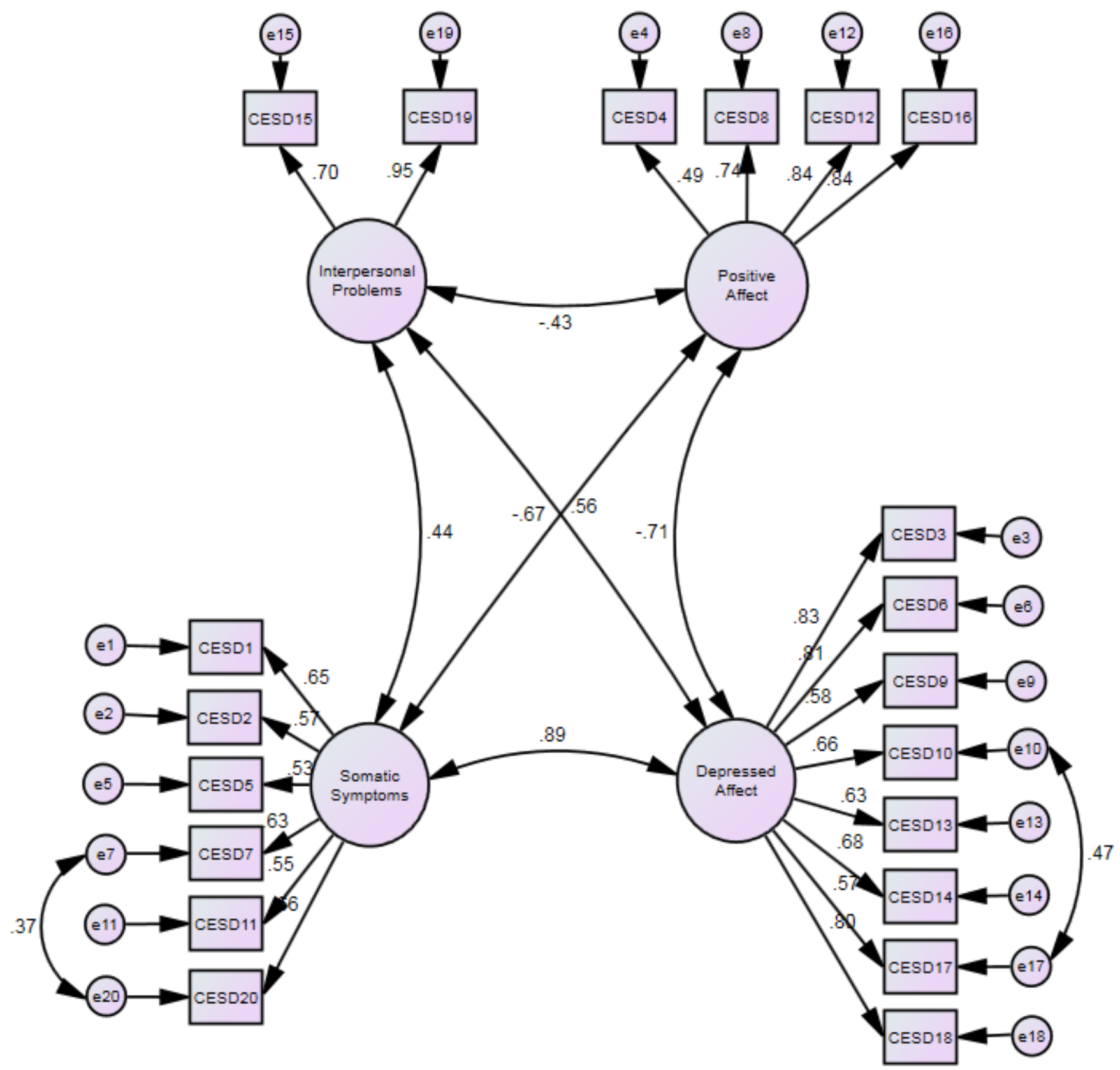

Figure 2. Revised CES-D model for People with MS - with all 20 items included. Figures are standardised maximum likelihood estimates.

either made trivial improvements in fit or did not make sense theoretically.

The re-specified model was then assessed in the confirmation sample (Model 4) and the fit indices suggest a satisfactory fit of this modified 4-factor model. Indeed, the fit indices are slightly better in the confirmation sample than the exploratory one. The modification made in the re-specification process did not imply factorially complex items nor that the basic 4-factor
CES-D model was substantively incorrect, so we estimated the standard Cronbach's Alpha reliability coefficients for the implied CES-D subscales in the confirmation sample. These were 0.81 for Positive Affect, 0.87 for Depressed Affect, 0.73 for Somatic Symptoms and 0.79 for Interpersonal Problems.

\section{Discussion}

The four-factor structure of the CES-D for the 19-item scale was supported by the factor analyses reported here. On the basis 
of these results, the English version of the CES-D has factorial validity in PwMS. Despite the potential contribution of neuropathology to symptoms, it does appear to have a coherent structure with which to examine depression in PwMS. Consistent with Shafer ${ }^{20}$, it supports the potential for considering the four factors in research such as that which might consider whether these factors vary as part of the natural course of co-existent depression or indeed that considers whether treatments might differentially affect the factors.

The main limitation of the current study is the typographical error we found in the questionnaire. We did not initially spot the typographical error (item 10 reads "I feel tearful" when it should read "I feel fearful"), and only noticed it after we conducted our initial analyses. It should be noted the compendium of instruments from which the CES-D was obtained is commonly available: it is held in many university and clinical departments. On this account we have contacted the First author of the compendium so notifications might ensue.

Interestingly, after a brief search for studies that give details of the CES-D items used we note that other studies ${ }^{36-39}$ have also included this (or a similar) version of the questionnaire, meaning their results will need to be re-evaluated. In fact, one Rasch analysis study using the CES-D in a rheumatoid arthritis sample $^{38}$ found differential item functioning on this item (which the authors present as "I felt tearful") for age and gender. The authors do suggest that this finding be replicated before a decision is made to remove this (and one other) item from the scale.
We could not complete a full review of the literature to determine how many other studies have used a version of the CES-D that includes the typographical error, and the impact this has on the findings from these studies. One of the problems is that not all authors report where they obtained the scale from, instead only citing the original reference of the scale. We were, however, able to spot the typo by looking for the word 'tearful' when item 10 is mentioned in the paper. On account of the error in the questionnaire, our modelling requires replication with all the full version of the CES-D. Nonetheless, despite this our result at this point are sufficient for us to be confident of how this this instrument would likely perform, that is, consistent with the four-factor solution.

\section{Data availability}

Underlying data

Consent was not obtained from participants for the sharing of their data, meaning that access to the data is restricted. Those wishing to access the data can apply for access. The data custodian is Prof Chris Fife-Schaw, University of Surrey (c.fife-schaw@surrey.ac.uk). Access will be provided to researchers at accredited institutions.

\section{Acknowledgements}

We wish to express our thanks to the MS Society of Great Britain and Northern Ireland for their assistance in obtaining participants for this study. Dr Helen Wain and Dr Sue Guerrier supported general administration and data analysis. Dr Emma Dunmore supported design of the longitudinal study project.
1. Mullins LL, Cote MP, Fuemmeler BF, et al.: Illness intrusiveness, uncertainty, and distress in individuals with multiple sclerosis. Rehabilitation Psychology. 2001; 46(2): 139.

Publisher Full Text

2. Browne $P, C$ handraratna $D$, Angood C, et al.: Atlas of multiple sclerosis 2013: a growing global problem with widespread inequity. Neurology. 2014; 83(11): 1022-1024.

PubMed Abstract | Publisher Full Text | Free Full Text

3. Wilkinson HR, Nair RD: The psychological impact of the unpredictability of multiple sclerosis: a qualitative literature meta-synthesis. British Journal of Neuroscience Nursing. 2013; 9(4): 172-178.

Publisher Full Text

4. Siegert R, Abernethy D: Depression in multiple sclerosis: a review. J Neurol Neurosurg Psychiatry. 2005; 76(4): 469-475.

PubMed Abstract | Publisher Full Text | Free Full Text

5. Skokou M, Soubasi E, Gourzis P: Depression in multiple sclerosis: a review of assessment and treatment approaches in adult and pediatric populations. ISRN Neurol. 2012; 2012: 427102.

PubMed Abstract | Publisher Full Text | Free Full Text

6. Brenner $P$, Burkill $S$, Jokinen J, et al: Multiple sclerosis and risk of attempted and completed suicide-a cohort study. Eur J Neurol. 2016; 23(8): 1329-1336. PubMed Abstract | Publisher Full Text

7. Feinstein A: Multiple sclerosis and depression. Mult Scler. 2011; 17(11): 1276-1281.

PubMed Abstract | Publisher Full Text

8. Messinis L, Kosmidis MH, Lyros E, Papathanasopoulos P: Assessment and rehabilitation of cognitive impairment in multiple sclerosis. Int Rev Psychiatry. 2010; 22(1): 22-34.

PubMed Abstract | Publisher Full Text
9. van Kessel K, Moss-Morris R, Willoughby E, et al.: A randomized controlled trial of cognitive behavior therapy for multiple sclerosis fatigue. Psychosom Med. 2008; 70(2): 205-213.

PubMed Abstract | Publisher Full Text

10. Lunde HMB, Aae TF, Indrevåg W, et al.: Poor sleep in patients with multiple sclerosis. PLoS One. 2012; 7(11): e49996. PubMed Abstract | Publisher Full Text | Free Full Text

11. Fischer A, Heesen C, Gold SM: Biological outcome measurements for behavioral interventions in multiple sclerosis. Ther Adv Neurol Disord. 2011; 4(4): 217-229.

PubMed Abstract | Publisher Full Text | Free Full Text

12. Gold SM, Krüger S, Ziegler KJ, et al.: Endocrine and immune substrates of depressive symptoms and fatigue in multiple sclerosis patients with comorbid major depression. J Neurol Neurosurg Psychiatry. 2011; 82(7): 814-818.

PubMed Abstract | Publisher Full Text

13. Rocca MA., Parisi L, Pagani E, et al.: Regional but not global brain damage contributes to fatigue in multiple sclerosis. Radiology. 2014; 273(2): 511-520. PubMed Abstract | Publisher Full Text

14. Zorzon M, Zivadinov R, Nasuelli D, et al.: Depressive symptoms and MRI changes in multiple sclerosis. Eur J Neurol. 2002; 9(5): 491-496. PubMed Abstract | Publisher Full Text

15. Hind D, O'Cathain A, Cooper, CL, et al.: The acceptability of computerised cognitive behavioural therapy for the treatment of depression in people with chronic physical disease: a qualitative study of people with multiple sclerosis. Psychol Health. 2010; 25(6): 699-712. PubMed Abstract | Publisher Full Text

16. Mohr DC, Goodkin DE, Likosky W, et al.: Identification of Beck Depression Inventory items related to multiple sclerosis. J Behav Med. 1997; 20(4): 
407-414.

PubMed Abstract | Publisher Full Text

17. Radloff LS: The CES-D scale: A self-report depression scale for research in the general population. Appl Psychol Meas. 1997; 1(3): 385-401. Publisher Full Text

18. Cole JC, Rabin AS, Smith, TL, et al.: Development and validation of a Raschderived CES-D short form. Psychol Assess. 2004; 16(4): 360-72. PubMed Abstract | Publisher Full Text

19. Pandya R, Metz L, Patten, SB: Predictive value of the CES-D in detecting depression among candidates for disease-modifying multiple sclerosis treatment. Psychosomatics. 2005; 46(2): 131-134.

PubMed Abstract | Publisher Full Text

20. Shafer $A B$ : Meta-analysis of the factor structures of four depression questionnaires: Beck, CES-D, Hamilton, and Zung. J Clin Psychol. 2006; 62(1): 123-146.

PubMed Abstract | Publisher Full Text

21. Wang $M$, Armour $C$, Wu $Y$, et al.: Factor structure of the CES-D and measurement invariance across gender in mainland Chinese adolescents. J Clin Psychol. 2013; 69(9): 966-979.

PubMed Abstract | Publisher Full Text

22. Thorson JA, Powell FC: The CES-D: Four or five factors? Bull Psychon Soc. 1993; 31: 577-578.

Publisher Full Text

23. Assari S, Moazen-Zadeh E: Confirmatory Factor analysis of the 12-item center for epidemiologic studies Depression scale among Blacks and Whites. Front Psychiatry. 2016; 7: 178.

PubMed Abstract | Publisher Full Text | Free Full Text

24. Choi $H$, Fogg $L$, Lee, EE, et al.: Evaluating differential item functioning of the CES-D scale according to caregiver status and cultural context in Korean women. J Am Psychiatr Nurses Assoc. 2009; 15(4): 240-248. PubMed Abstract | Publisher Full Text | Free Full Text

25. Williams, CD, Taylor TR, Makambi K, et al:: CES-D four-factor structure is confirmed, but not invariant, in a large cohort of African American women. Psychiatry Res. 2007; 150(2): 173-180. PubMed Abstract | Publisher Full Text

26. Amtmann D, Kim, J, Chung, $\mathrm{H}$, et al.: Comparing CESD-10, PHQ-9, and PROMIS depression instruments in individuals with multiple sclerosis. Rehabil Psychol. 2014; 59(2): 220

PubMed Abstract | Publisher Full Text | Free Full Text

27. Verdier-Taillefer $\mathrm{MH}$, Gourlet V, Fuhrer $\mathrm{R}$, et al: Psychometric properties of the Center for Epidemiologic Studies-Depression scale in multiple sclerosis. Neuroepidemiology. 2001; 20(4): 262-267.

PubMed Abstract | Publisher Full Text

28. Comrey AL: Common methodological problems in factor analytic studies.
J Consult Clin Psychol. 1978; 46(4): 648-59.

Publisher Full Text

29. Simón A: Effects of selective sampling on a factor analysis. The Journal of General Psychology. 1979; 101(2): 259-264.

Publisher Full Text

30. Mokkink LB, Terwee CB, Patrick DL, et al.: The CoSMIN checklist manual. 2012. Accessed November 2019. Reference Source

31. Kneebone II, Guerrier S, Dunmore E, et al.: A longitudinal examination of the hopelessness theory of depression in people who have Multiple Sclerosis. Behav Neurol. 2015; 2015: 190405.

PubMed Abstract | Publisher Full Text | Free Full Text

32. Devins GM, Orme CM, Costello CG, et al: Measuring depressive symptoms in illness populations: Psychometric properties of the Center for Epidemiologic Studies Depression (CES-D) scale. Psychology and Health. 1988; 2(2): 139-156.

Publisher Full Text

33. Hu LT, Bentler PM: Cutoff criteria for fit indexes in covariance structure analysis: Conventional criteria versus new alternatives. Struct Equ Modeling Multidiscip J. 1999; 6(1): 1-55.

Publisher Full Text

34. Hayduk LA: Structural equation modeling with LISREL: Essentials and advances. The John Hopkins University Press: Baltimore, MY. 1987. Reference Source

35. Johnston M, Wright S, Weinman J: Measures in health psychology: a user's portfolio. NFER - Nelson. 1995

Reference Source

36. Schroevers MJ, Sanderman R, Van Sonderen E, et al. The evaluation of the Center for Epidemiologic Studies Depression (CES-D) scale: depressed and positive affect in cancer patients and healthy reference subjects. Qual Liife Res. 2000; 9(9): 1015-1029.

PubMed Abstract | Publisher Full Text

37. Takeuchi $\mathrm{H}$, Hiroe $\mathrm{T}$, Kanai T, et al.: Childhood parental separation experiences and depressive symptomatology in acute major depression. Psychiatry Clin Neurosci. 2003; 57(2): 215-219. PubMed Abstract | Publisher Full Text

38. Covic T, Pallant JF, Conaghan PG, et al:: A longitudinal evaluation of the Center for Epidemiologic Studies-Depression scale (CES-D) in a rheumatoid arthritis population using Rasch analysis. Health Qual Life Outcomes. 2007; 5:

PubMed Abstract | Publisher Full Text | Free Full Text

39. Covic T, Pallant JF, Tennant A, et al.: Variability in depression prevalence in early rheumatoid arthritis: a comparison of the CES-D and HAD-D Scales. BMC Musculoskelet Disord. 2009; 10: 18.

PubMed Abstract | Publisher Full Text | Free Full Text 


\section{Open Peer Review}

\section{Current Peer Review Status:}

\section{Version 1}

Reviewer Report 01 February 2021

https://doi.org/10.5256/f1000research.27732.r76797

(C) 2021 Piri Cinar B. This is an open access peer review report distributed under the terms of the Creative Commons Attribution License, which permits unrestricted use, distribution, and reproduction in any medium, provided the original work is properly cited.

\section{Bilge Piri Cinar}

Zonguldak Bülent Ecevit University, Zonguldak, Turkey

1. This depression scale is not used very often in MS. For this reason, it is recommended that the reason for choosing this scale should be briefly explained in the introduction part of the comparison studies with other scales.

2. When the models in the article are examined in the source where values such as SRMR and RMSEA are referred, the models seem sufficient. The general outline of the study is welldesigned and the statistical approach has its strengths in general.

3. It is recommended to indicate whether the sample size has been calculated or not.

4. According to a general rule, it is stated that the number of items recommended for the study group to use the factor analysis technique or the sample size five times the number of observed variables (Child, $2006^{1}$ ). According to Kline (1994²), although it is recommended to keep the item (variable) ratio 10: 1 for the sample size, it is stated that this ratio can be reduced, but should be at least $2: 1$. It is recommended to give information about the sample size in the method section.

5. The suitability of the dataset for factor analysis is recommended to be detailed in the statistics section (normal distribution ...).

6. It would be appropriate to write explanations and abbreviations under the tables and figures.

\section{References}

1. Child D: The Essentials of Factor Analysis. Continuum. 2006; 3rd Edition. Reference Source

2. Kline P: An Easy Guide to Factor Analysis. 2014. Publisher Full Text

Is the work clearly and accurately presented and does it cite the current literature? 
Yes

Is the study design appropriate and is the work technically sound?

Yes

Are sufficient details of methods and analysis provided to allow replication by others? Partly

If applicable, is the statistical analysis and its interpretation appropriate?

I cannot comment. A qualified statistician is required.

Are all the source data underlying the results available to ensure full reproducibility? Partly

Are the conclusions drawn adequately supported by the results?

Yes

Competing Interests: No competing interests were disclosed.

Reviewer Expertise: I am an expert in the field of MS. In all my studies, I definitely consider the presence of depression in patients. In our MS clinic, we routinely use different depression scales in practical life.

I confirm that I have read this submission and believe that I have an appropriate level of expertise to confirm that it is of an acceptable scientific standard.

Reviewer Report 07 October 2020

https://doi.org/10.5256/f1000research.27732.r71819

(C) 2020 Kaklamanou D. This is an open access peer review report distributed under the terms of the Creative Commons Attribution License, which permits unrestricted use, distribution, and reproduction in any medium, provided the original work is properly cited.

\section{Daphne Kaklamanou}

Department of Psychology, University of Portsmouth, Portsmouth, UK

This is an interesting article that is looking at the factor structure of the CES-D scale for PwMS. The study has a really good sample size to complete the analysis and draw conclusions from.

Overall the introduction seems to cover most of the literature in the area, although the systematic review (Hind et al., 2016 ${ }^{1}$ ) on the reliability and validity of depression inventories for PwMS is missing, so the authors might want to check that they have not missed anything. Also it would be good to explain why the authors chose the CES-D scale rather than other depression inventories.

For the Method section, there seems to be some detail, but more detail of the CES-D scale factor 
structure and the items would be good and would help understand the discussion in terms of the factors. In terms of the participants, it is clearly stated that this is a study that has taken place over a long period of time but providing a bit more detail (1) on the exact time/year; (2) over how long did they collect the data that are analysed in the study; (3) were there any other measurements collected e.g. other depression measures or the Gold standard the interview.

At some in the method section the authors state that "the CES-D data collected at phase 1 are reported here", I presume they mean the current study.

\section{References}

1. Hind D, Kaklamanou D, Beever D, Webster R, et al.: The assessment of depression in people with multiple sclerosis: a systematic review of psychometric validation studies. BMC Psychiatry. 2016; 16

(1). Publisher Full Text

Is the work clearly and accurately presented and does it cite the current literature? Partly

Is the study design appropriate and is the work technically sound?

Yes

Are sufficient details of methods and analysis provided to allow replication by others? Partly

If applicable, is the statistical analysis and its interpretation appropriate? Yes

Are all the source data underlying the results available to ensure full reproducibility? Partly

Are the conclusions drawn adequately supported by the results?

Yes

Competing Interests: No competing interests were disclosed.

Reviewer Expertise: I have done work looking at the reliability and validity of depression inventories for PwMS and looked into user experience of depression inventories in PwMS.

I confirm that I have read this submission and believe that I have an appropriate level of expertise to confirm that it is of an acceptable scientific standard. 
The benefits of publishing with F1000Research:

- Your article is published within days, with no editorial bias

- You can publish traditional articles, null/negative results, case reports, data notes and more

- The peer review process is transparent and collaborative

- Your article is indexed in PubMed after passing peer review

- Dedicated customer support at every stage

For pre-submission enquiries, contact research@f1000.com 